\title{
Knife in the Clean Water: Life Reality in Border Area and Personal Narrative Experience
}

\author{
Guangwen Liu \\ The College of Literature and Journalism \\ Sichuan University \\ Chengdu, China
}

\begin{abstract}
In the narrative tradition of realism, the film "Knife in the Clean Water" mirrors the border areas far from the Chinese film culture center. On the theme, the Chinese realist films creation in the multiple integration pattern were supplemented and improved. The director completed the film creation in the way of ethnographic narrative. In the ethnographic narrative, the real life of the ethnic groups in the border areas and the personal experience of the Han national directors are integrated into the introspective thinking of life, so as to achieve dialogue and observation between life and self between different ethnic groups.
\end{abstract}

Keywords-"Knife in the clean water"; ethnography; border areas; personal narrative

\section{INTRODUCTION}

The film "Knife in the Clean Water" was adapted from Shi Shuqing's novel of the same name. In 2016, he won the New Wave Award at the Busan Film Festival. The final file was screened on April 4, 2018.In the barren countryside of the Xihaigu area in Ningxia, the wife of the Hui national elderly Ma Zishan passed away. The son proposed to his father to kill the only cattle in the family to complete the memorial ceremony on the fortieth day after the mother died. The story of the film took place during the period from the death to the day of memorial ceremony, depicting the inner feelings of the old man, and also performing a performance on the daily life of the people on this land. In the simple and gentle lens narrative, the film explores life issues such as life and death and intergenerational conflicts, allowing the audience to feel the heavy life force and make an anthropological view of people, things and objects in the Xihaigu area.

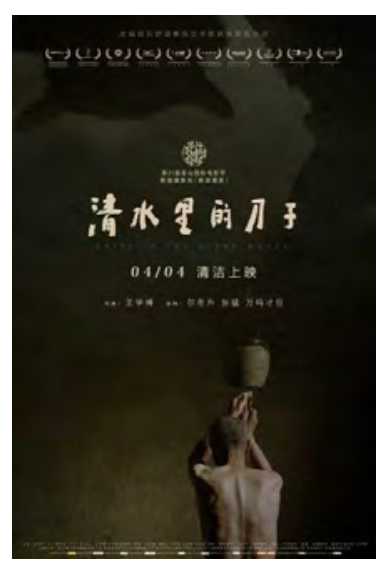

Fig. 1. The movie poster Knife in the Clean Water.

\section{REALISM BORDER AREAS MIRROR}

Realism has always been the most striking feature of the Chinese film tradition. What is the most profound impression of the Chinese film from the budding period to the present? Realism and sense of the times, with that Western can understand China through Chinese movies.[1] The "Knife in the Clean Water" as border areas mirror continues this tradition of realism, with a simple and simple image, meticulously restore the natural landscape, people and their lives of Xihaigu. Real-life shooting, non-professional actors, simultaneous sounds, regional dialects, and 4:3 frames all show similarities to Italian neo-realism. In order to pursue more extreme realism, the whole movie did not even use a piece of music. According to director Wang Xuebo, this is to achieve a more "simplified" effect.[2] Music as one of the film languages is "simplified" to missing in the film, and the dialect dialogue and environmental sound effects that follow the "simplification" principle make the film more realistic.

Realism is not only the style characteristic of the film's external form, it is also the choice and excavation of the theme. The reason why Italian neo-realism and French New Wave have a strong influence in the history of film is that they focus on expressing people's survival dilemma and caring for people. The sixth generation of directors focused on the social marginal groups such as rock youth, social gangsters, urban migrant workers, and laid-off workers. But this group of young directors who used to be the new force 
of Chinese film collectively their realist narratives in the city, the center of this modern civilized region, few people turned their shots to the border rural areas where ethnic minorities lived together. "Knife in the Clean Water" takes a grand multi-ethnic country as its narrative vision and mirrors the border areas of the film culture. Xihaigu is located at the southern end of the Ningxia Hui Autonomous Region, leaning against Liupan Mountain. Until today, China's film theory circles are still based on the dualism of the Han and the "minority". It is often seen as border area away from the center of film culture, and rarely won the favor of the film culture circle. The Knife in the Clear Water is the core of the narrative of the Huieldly Ma Zishan's family. The intergenerational conflict between his son and his son, his affection for his deceased wife, his help to the neighbors, and his unwillingness to bear the cows have given the Chinese audience an opportunity to understand the living conditions, Mental state, etc. of this border area, and reflects a strong humanistic care. Therefore, the meaning of "Knife in Clean Water" is to supplement and improve the theme of Chinese realist film creation in the multiple integration patterns.

In "Knife in the Clean Water", the border area mirror is no longer a spectacle show in the movies of ethnic minorities. Although the film also has the customs of local Hui people such as the burial of the dead, the name of the newborn, the Muslim worship, and the sacrifice of the cattle, the director's narrative treatment did not deliberately highlight the mystery of these national customs. Although the whole story was unfolded in the barren countryside of Xihaigu, the film framing did not show the natural landscape of the gully in the Loess Plateau. The director also said: "I think this is part of their life. This environment can't avoid some religious rituals. I didn't think about circumventing it, but I didn't have the intention of preaching. For example, the contents of the local chanting were not translated. Because there is no specific meaning to convey, it is just a scene of life."[3] Avoid the spectacle of the national customs, and replace this part with a bland image of life. No longer singularly, no longer regard border areas as "them" other than "us", so as not to let the film of ethnic minorities embark on the path opposite to the realist tradition, and enter the desperate distortion of reality and the loss of artistic vitality.

\section{PERSONAL EXPERIENCE OF ETHNOGRAPHIC NARRATIVE}

The anthropological approach emphasizes field work and completes the writing of ethnography by entering the field to participate in observation. Ethnography is generally regarded as a narrative about the culture of a different nation. Write what you see and hear about people from different places to people like yourself. This kind of writing is classified as ethnography.[4] The director Wang Xuebo was a Han nationality. Before filming the movie "Knife in the Clean Water", he entered the rural experience of Xihaigu in 2010 for 10 months [5]. Then, in the form of a movie, a cultural narrative equivalent to the ethnographic writings of anthropologists such as Malinowski was reached.

Although the film's screenwriter is Shi Shuqing, the original writer of Hui, but to achieve the skills of not being directed by the director with the Han culture, a solid field investigation is essential. Only by immersing the creator in the Xihaigu village completely, by participating in the experience of specific local life, scientific ethnographic narrative can be obtained. The film always shows a gentle narrative style, just as the days of the people living here are as calm as possible, and the contradictions in life are included. At the beginning of the film, there was a scene about death. The director did not use a lot of shots to render the local ritual atmosphere, but it was taken in a simple way, making the funeral look ordinary. The adults chased the children took back the fire sticks. The dry land ushered in a rare rain the whole family went out to dig alfalfa for the cows and use the containers to pick up the rain. All the plots and scenes were very lively, and there was no trace of artificial rehearsal. Even with the religious ceremonial scenes of the name the newborn, worship, ghusl, and the rescue of the dead, the director is simplifying the process, and the picture and plot are not too complicated. For example, after the children of the family who borrowed rice from the neighbors were born, the imam who came from the temple mourned a few simple verses at the door, and then said the child's name, and the ceremony ended. Even the slaughtering ritual, which is the core driving force of the film narrative, is "simplified".

However, in any case, ethnographic narratives naturally contain personal narrative. The personal narrative originating from early personal travels has not been weakened by the scientific status of ethnography, and it is still the regular form of ethnographic narrative. [6] Personalizing the film is also a routine requirement of the film theory of the film art. For example, the sixth generation director Wang Xiaoshuai specifically stated "a movie of Wang Xiaoshuai" on the title of his work "Day of Winter and Spring". Director Wang Xuebo, who has received professional education, is undoubtedly the practitioner of the author's film theory. The "minimalist" and "clean narrative" of "Knife in the Clean Water" [7] can be regarded as a personal narrative formed by the director in this film in the sense of ethnographic narrative. The reason why the personal narrative of ethnographic writing mentioned above has not been weakened by science is that it can mediate the contradiction between "engagement" and "self-effacement" and repair different cultures. [8] Therefore, as the personal narrative is necessary in ethnographic writing, the integration of the director's personal experience is also an indispensable part of the author's film creation process. In fact, there is no such thing as a contradiction between personal narrative and realism. The realist narrative of the sixth generation of directors is globally recognized because of his personal experience, and pushes the connotation of realism to a deeper level. "The idea that 'my camera doesn't lie' is not just about the reality of the film's attention to social content, but also that the film reflects the true feelings and the reality of life experience of the creator, thus becoming the 'author film' in the true sense." [9] "Knife in Clean Water" is undoubtedly the inheritance of the sixth generation of creative ideals. It interprets the essence of Xihaigu regional culture in the two dimensions of "minimalism" and "clean narrative" of personal experience. 
Of course, this interpretation is also the result of a dialogue between them.

\section{PEOPLE-ORIENTED LIFE INTROSPECTION}

Watching "Knife in the Clean Water" is like experiencing a life sentiment, as if you have lived through this world and saw the afterlife, it is like a meditation after you unload your armor and heavy makeup layer by layer.

From the beginning, the film went straight into the subject of life. The first scene described the burial of his wife after death, followed by a sacrifice in which the son and the old man negotiated forty days' memorial ceremony. The latter scene as the core of the film narrative is also the start that causes us to think about what life is and what people are. The son said that his mother had lived in the world for a lifetime without the appearance of a "person". After the death, the memorial should be taken seriously to "save the dead." The mother is not only the "person" without the appearance of a "person" in the lines, but also the "person" without the appearance of a "person" in the film's shot. Life is beyond the flesh. The disillusionment of the flesh does not mean the end of life. Therefore, it is necessary to "rescue" the dead to become a "person", a complete "person". The mother did not live as a "person" in the life course of this part of the world, so the son who wants to slaughter the cattle as an important means of production is to "save the dead" and let the mother's later life have the appearance of a "person". The absence mother is more like a metaphorical symbol of "death". The symbol corresponding to the mother is the newborn baby, and he becomes the symbol of "life". The imam's naming ritual is for him short but not sacred. The old man who is sincere and quiet is not only expressing awe of God, but also expressing awe of the life and died. From the death of his wife to the birth of a baby, to the slaughtering ceremony at the end, the film realizes a cycle from death to life and from birth to death. Life is "predetermined" and death is "return" [10]. Therefore, in the film, people have no joys and sorrows in front of life and death. Just like the calmness of the film in terms of narrative techniques, the Hui people also face life with a calm attitude.

The poster of the film reads the words "Clean Release". "Cleaning" is the introspection of the cow's life in the face of death. Local folklore cows can see the knife in the water they drink a few days before they die, and then start not to eat or drink, clean the inside. "Cleaning" became an eye for this work. The film title "Knife in the Clean Water" comes from local folklore. However, the content of the video is contrary to it. The loess that is annihilated everywhere is the intrinsic landscape of Xihaigu, and it is also a description of the life of people. The alfalfa was scattered in the ground, and there was a layer of loess on it. The rain that rained on the rainy days was also muddy. It is the people who live in such an environment where the mountains are not clear and watery, but they have the concept of supreme "cleanness" in the object of "water" associated with life. Life is clean for cattle, let alone people? As a large animal of sacrifice, cattle have already been associated with human life. The old man constantly asks the wise man in the village the folklore of "the knife in the clean water". It is not so much the relationship between the person and the cow. It is said that it is the result of people's self-life and the expression of the local life. The subtle emotions of Ma Zishan's psychology described in the film "Knife in the Clean Water" seem to point to his wife and point to the cow, but actually point to his own life. Until the last shot of the film, the earth was covered with snow, and the old man looked at his wife's graveyard and realized the complete "cleaning" of life.

\section{CONCLUSION}

"Knife in the Clean Water" is like a life song that has not been wrapped in modern electronic instrumental music. From the beginning to the end, the film implements the principle of simplicity, and the scene, lens, sound, and narrative are extremely simplified. Even the folklore that is at the heart of the story is done in the reflection of the old man and the cow on a simple water surface. It did not directly photograph the presence of a knife in the clear water from the subjective point of view of the cow, omitting the object of "knife" in the clear water. The simplicity of the object is not concise in meaning. On the contrary, the meaning of the image is extremely full. In this rough and sloping loess plateau, in the folk stories that have been circulating for thousands of years, the life and life landscape of people have been slowly spread out. As a universal proposition of humanity, life is tenacious and open-minded here. The film "Knife in the Clean Water" incorporates the reality of the border ethnic group and the personal experience of the Han creators from the film center cultural district into the introspection of life in a simplified daily narrative. In this way, we have realized the grand vision of understanding life and understanding ourselves in dialogue and watching between different ethnic groups.

\section{REFERENCES}

[1] ShuXiaoming: "Chinese Film Art History Tutorial", China Film Press, 1996, p. 132. (in Chinese)

[2] Wang Xuebo, Ye Hang, Zhou Tianyi: "Life and Death, Simple and Complex - Interview with <Knife in the Clean Water $>$ Director Wang Xuebo", Journal of Beijing Film Academy, 2017(03):93-99. (in Chinese)

[3] Wang Xuebo, Ye Hang, Zhou Tianyi: "Life and Death, Simple and Complex - Interview with $<$ Knife in the Clean Water $>$ Director Wang Xuebo", Journal of Beijing Film Academy, 2017(03):93-99. (in Chinese)

[4] GaoBingzhong: "The Three Times of the Development of Writing Culture and Ethnography", (United States) James Clifford, George E. Marcus, "Writing Culture - Poetics and Politics of Ethnography", translated by GaoBingzhong, Wu Xiaoli, Li Xia, etc., Commercial Press, 2014, p. 6. (in Chinese)

[5] Reference Wang Lei: "He spent ten years, filmed a movie about the Hui people", WeChat public number: Adventure movie (ID: cinematik) 2016.10.7. (in Chinese)

[6] Reference to Mary Louise Pratt: "Field work in the Common Land", translated by Zhou Xinhong, (US) James Clifford, George E. Marcus, "Writing Culture - Poetics and Politics of Ethnography" ,translated by GaoBingzhong, Wu Xiaoli, Li Xia, etc., The Commercial Press, 2014, p. 61. (in Chinese)

[7] Wang Xuebo, Ye Hang, Zhou Tianyi: "Life and Death, Simple and Complex - Interview with $<$ Knife in the Clean Water $>$ Director 
Wang Xuebo", Journal of Beijing Film Academy, 2017(03):93-99. (in Chinese)

[8] The discussion of "self-discipline" and "self-stealth", please refer to Mary Louise Pratt: "Field work in the Common Land", translated by Zhou Xinhong, (US) James Clifford, George E. Marcus editor, "Writing Culture - Poetics and Politics of Ethnography", translated by GaoBingzhong, Wu Xiaoli, Li Xia, etc., The Commercial Press, 2014, p. 62. (in Chinese)

[9] XuJinghan: "The Camera That Does Not Lie" — Deepening the Experience of Contemporary Chinese Film Realism Imaging, Contemporary Cinema, 2013 (07): 110-114. (in Chinese)

[10] For the thoughts of "predetermination" and "regression" in the concept of Muslim life and death, please refer to Li Xuezhong: "The Funeral Customs of the Hui People and the View of Life and Death of Muslims", Ningxia Social Science, 1998 (01): 82-87. (in Chinese) 